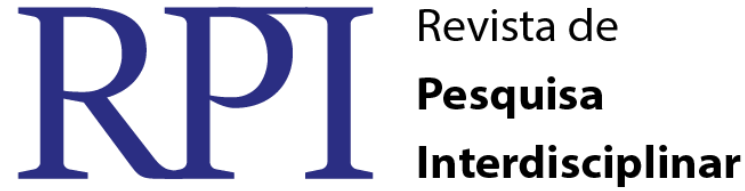

\section{O CORPO E ALGUNS INDÍCIOS DE REPRESENTAÇÕES SOCIAIS DELINEADAS NO IMAGINÁRIO DOCENTE}

\author{
Otávio Barreiros Mithidieri- UTAD/UNIFOA ${ }^{1}$ \\ Ana Paula Monteiro - UTAD/Pt $)^{2}$
}

\begin{abstract}
RESUMO
$\mathrm{O}$ artigo versa sobre as representações sociais de corpo para professores de uma escola da rede pública do estado do Rio de Janeiro, como fruto de discussões educacionais, atualmente, no Brasil, que reclamam pela ideia da realização de estudos e pesquisa ser para uma intervenção colaborativa. Daí, destacar que o artigo apresenta as discussões primeiras do projeto de doutoramento na UTAD com o objetivo de apreender as representações sociais de corpo para professores e daí analisar como inferem na relação aluno-professor. Nesse sentido o estudo visa coroborar com o pensar a constituição da corporeidade na Baixada Fluminense, no município de Duque de Caxias. O cenário neste munícipio é caótico. Trata-se de uma cidade próxima a $14 \mathrm{~km}$ da capital Rio de Janeiro. Caxias, como é conhecida, é a cidade sem "anjos", marcada por violência social, desvio de verbas da educação, escândalos políticos apagados pela força econômica de grandes empresários que se nutrem da miséria para formação e manutenção do curral eleitoral. Distancia-se das belezas naturais e imagens midiáticas vendidas pelo mundo a fora, da cidade maravilhosa, cantada por Vinicius de Moraes ${ }^{3}$.
\end{abstract}

Palavras-chave: Corpo. Teoria das Representações Sociais. Educação

\section{THE BODY AND SOME INDICES OF SOCIAL REPRESENTATIONS DESIGNATED IN THE TEACHING IMAGINARY}

\begin{abstract}
The article deals with the social representations of body for teachers of a public school in the state of Rio de Janeiro, as a result of educational discussions, currently in Brazil, that demand for the idea of conducting studies and research be for a collaborative intervention . Hence, it should be noted that the article presents the first discussions of the doctoral project at UTAD with the objective of apprehending the social representations of the body for teachers and hence analyzing how they infer in the student-teacher relationship. In this sense, the study aims to corroborate with thinking the constitution of corporeity in Baixada Fluminense, in the city of Duque de Caxias. The scenery in this town is chaotic. It is a city about $14 \mathrm{~km}$ from the capital Rio de Janeiro. Caxias, as it is known, is the city without "angels", marked by social violence, misappropriation of education, political scandals erased by the economic strength of big businessmen who are fed by misery for the formation and

\footnotetext{
${ }^{1}$ Doutorando em Educação pela Universidade de Trás-os-Montes e Alto Douro - UTAD, Portugal, Professor do Centro Universitário de Volta Redonda, professor do Instituto de Educação Prof. Manuel Marinho da Secretaria de Estado de Educação do Rio de Janeiro, Implementador de Educação Física da Fundação Educacional de Volta Redonda.

${ }^{2}$ Professora Auxiliar no Departamento de Educação e Psicologia. Doutora em Psicologia Social e Básica pela Universidade de Santiago de Compostela. Membro da Comissão Editorial da Revista Electrónica de Educação e Psicologia (EduPsi).
}

3 Música Cidade Maravilhosa é marchinha de carnaval escrita pelo compositor, arranjador, cantor, multiinstrumentista (piano, violão, bandolim, violino, banjo, percussão) e radialista Antônio André de Sá Filho, o Andre Filho (21 de março de 1906 - 2 de julho de 1974 - Rio de Janeiro).
\end{abstract}


maintenance of the electoral corral. It distances itself from the natural beauties and media images sold by the outside world, from the wonderful city, sung by Vinicius de Moraes.

Keywords: Body. Theory of Social Representations. Education

\section{INTRODUÇÃO}

Em espaços urbanos com características de violência fisica e subjetiva, propiciada pelo sistema capitalista vigente, cabe explorar as formas de representações que emergem nesses espaços-tempos por meio de diálogo entre a universidade e as Escolas para se compreender os caminhos possíveis para transformação dos jovens pela educação. Esta só ocorre se o professor se colocar diante da educação como corresponsável por este processo transformador, como já assinalava Paulo Freire (FREIRE; SHOR; 1986; FREIRE, 1996; 2005).

Entendemos com Moscovici, (1979, 2003), que as representações, ou formas de conhecimento impõem certas práticas, daí propor aprofundar os estudos com matriz teórica na Teoria das Representações Sociais no que ela elucida acerca dos fenômenos educativos, em especial a Formação de Professores. Portanto, partiremos do pressuposto de que a imagem de si manifesta na linguagem corporal influencia o professor no seu desempenho.

Enfim, acreditamos que as representações sociais de corpo podem indicar os preconceitos e dificuldades no enfrentamento dos temas tabus na contemporaneidade.

Aqui o objetivo é apresentar algumas ideias iniciais do projeto de doutoramento na UTAD a partir da revisão sobre as representações sociais.

Importa esclarecer que para o desenvolvimento das pesquisas associadas ao Lageres adota-se a abordagem etnográfica (BREWER, 2009), envolvendo a história oral temática (MEIHY; RIBEIRO, 2011), como estratégia de base. O volume de dados coletados, já nos permite estabelecer focos específicos de análise pareada para que os resultados sejam apresentados aos professores da escola em estudo para aprofundamento do mesmo.

Ainda esclarecemos que após a observação ao longo de dois anos de trabalho sobre o corpo, no Lageres, levantamos o diagnóstico da dificuldade do professor em estudo de solucionar sozinhos os problemas encontrados no cotidiano diante de tema tabus. Assim, a pergunta de partida do projeto de pesquisa, originário do presente artigo foi: Quais são as representações sociais de corpo para as professores do CIEP098? Considerando a pergunta RPI Revista de Pesquisa Interdisciplinar, Cajazeiras, v. 1, Ed. Especial, 114 - 128, set/dez. de 2016. 
de partida deste estudo: Quais são as representações sociais de corpo para as professores do CIEP098? Assim, a problemática que poderá dar resposta à pergunta formulada centra-se na relação existente entre as representações sociais de corpo a superação de temas tabus em prol da melhoria do processo de ensino/aprendizagem. Nesta perspetiva, entendemos como linha condutora da nossa problemática a seguinte abordagem:

Em termos de pesquisa, esta escolha surge pela necessidade de compreender como as representações sociais de corpo inferem na relação aluno-professor. Estabelecemos a proposta de natureza interdisciplinar (POMBO, 2004), que perpassará pela filosofia, sociologia e a psicologia social, sob a luz da Educação, para se elucidar a relação entre as representações sociais sobre o corpo e a linguagem corporal no enfrentamento de temas "tabus" na formação de professores. Deste modo será possivel responder a questões singulares, locais e, ao mesmo tempo possa ser generalizadas, respeitando os diversos contextos sociais em que a práxis educativa esteja inserida.

O artigo está dividido em cinco dimensões de estudo, conforme proposto por Novikoff (2010), ou seja, etapas de desenvolvimento da pesquisa dialéticamente entre as dimensões epistemológica, teórica, metodológica, morfológica e analítico-conclusiva. Estas são descritas no tópico metodologia deste documento.

\section{Fundamentação Teórica}

O corpo como ambiente "onde transcorre um enorme trabalho simbólico e onde é realizada uma imensa produção simbólica (...), também é objeto de regulações sociais.” (TURNER, 2014, p. 253 in JACÓ-VILELA; SATO, 2012). Regulações estas que advém de instituições distintas, mas que aqui nos interessa é a escola e a negligência sobre o corpo como criatura encarnada e socialmente construída e constituída, para além da biologia.

O corpo é o espaço-tempo do sujeito/coletivo que se presentifica em muitos discursos não ditos. Noutras palavras, o ausente está presentificado nos discursos, na linguagem como diria Santaella. Ele está na voz, no gesto, no comportamento, na garatuja e traços do homem/mulher. Aquilo que não é dito se faz e é feito no ausente.

A escola enquanto lugar do desenvolvimento social, cognitivo, afetivo e psicomotor, nem sempre trabalha o corpo, em razão dos corpos ausentes dos próprios professores. Estes carregam, em sua maioria, uma representação social de corpo, enclausurada na psiquê, que só 
um estudo da zona muda (ABRIC) poderia nos dar alguns indícios (GRINZBURG) dos sentidos de corpo.

Para ser professor/professora precisa sentir o outro e sentir-se. No entanto, o sentir depende da perspectiva do outro, da alteridade, mas onde entraria o corpo? Por todos os lados que se observa lá está o corpo, morada da alma, se faz presente por diferentes caminhos. De Maturana, apreendemos a ideia do relacional, com as emoções que agem. Aqui dialogo com Morin e assinalo o corpo como complexo tema que exige/clama pela interdisciplinaridade de Japiassú - o diálogo com o outro para pensar o corpo presente, mas, também, ausente em seus muitos significados. Significado ausente que muito diz do momento presente de professores com representações carregadas da imagem de si - sou ou não sou, o que gostaria de ser.

Para apresentar as primeiras ideias sobre o tema são delineadas as possíveis articulações epistemológicas a partir do levantamento de alguns conceitos e ideias sobre representações sociais e de corpo.

\section{Representações sociais: noções preliminares}

As representações sociais pautadas na teoria das Representações Sociais de Moscovici (1961, 1979, 2003) podem ser entendidas como forma de conhecimento que se origina da necessidade do sujeito tornar o não-familiar em familiar e se institui na intersubjetividade e sustentam práticas frente ao cotidiano.

Com o entendimento acima pincelado, entra a importância da intersubjetividade na formação docente. E, segundo Jodelet (2009) a esfera de intersubjetividade

[...] remete às situações que, em um dado contexto, contribuem para o estabelecimento de representações elaboradas na interação entre os sujeitos, apontando em particular as elaborações negociadas e estabelecidas em comum pela comunicação verbal direta. São numerosos os casos que ilustram o papel da troca dialógica de que resultam a transmissão de informação, a construção de saber, a expressão de acordos ou de divergências a propósito de objetos de interesse comum, a interpretação de temas pertinentes para a vida dos participantes em interação, a possibilidade de criação de significações ou de ressignificações consensuais (JODELET, 2009, p. 698).

A representação social para Abric é "produto e processo de uma atividade mental pela qual um indivíduo ou um grupo reconstituído realidade, portanto, confronta e lhe atribui um significado específico" (ABRIC, 1976, p. 54). E exatamente esta noção que abre o campo para RPI Revista de Pesquisa Interdisciplinar, Cajazeiras, v. 1, Ed. Especial, 114 - 128, set/dez. de 2016. 
a percepção social, quando o autor diz: "estes processos de opinião social são, portanto, elementos-chave, aparentemente compostas de pensamento social, que permitem classificar e compreender a realidade vivida por indivíduos ou grupos" (idem, p. 64).

A representação social, segundo Jodelet (2001, p. 27), "é uma representação sempre de alguma coisa (objeto) e de alguém (sujeito)”. Assim, as características dos sujeitos e objetos são reveladas entre si, não se separam, mas se distinguem, como diria Morin (1994) . Então, podemos deduzir que existem múltiplas forças que forjam o corpo, como as imagens da mídia, os sistemas normativos e sociais sobre alimentação, vestimenta, atitude. E, em relação ao corpo representado pelo docente podemos pensar nas suas formas de regulação ou emancipação, analisando diferentes forças de determinação como a política de formação, a atuação profissional, as condições de trabalho, entre outras. Cremos que a literatura da sociologia, da psicologia social e filosofia possam nos indicar quais representações de corpo está sendo instituída na escola e avaliar numa realidade social específica para identificar e compreender o ensino como fato social que está sendo formado ou deformado. Vale destacar que as representações têm funções diferenciadas para tornar o não-familiar em familiar. O que não está familiar para o professor? Como está agindo para torna-lo familiar? São algumas das questões a serem discutidas no decorrer do estudo que pretendemos continuar a realizar no CIEP098.

Vale destacar que toda representação tem uma face figurativa e uma face simbólica indissociável como a frente e o verso de uma folha de papel. Ou seja, a representação "(...) faz compreender a toda figura um sentido e a todo sentido uma figura" (MOSCOVICI, 2003, p. 65). Através dessa configuração o autor explica os processos formadores de representações sociais. A objetivação carrega a função de duplicar um sentido por uma figura, materializando o objeto. Tem-se como exemplo o fato de um complexo (conceito psicanalítico) tornar-se um órgão psicofísico do sujeito. A ancoragem tem a função de duplicar uma figura por um sentido. Sá (1993, p. 34) explica que esse processo consiste em “(...) fornecer um contexto inteligível ao objeto, interpretá-lo (...)". Esse mesmo autor cita como exemplo o fato de a análise ser comparada ou definida como uma espécie de confissão religiosa. Assim, o distanciamento de si e do outro dificulta a compreensão do papel politico e social da educação.

\section{O corpo e sua linguagem corporal}

RPI Revista de Pesquisa Interdisciplinar, Cajazeiras, v. 1, Ed. Especial, 114 - 128, set/dez. de 2016. 
É a compreensão da linguagem corporal que trazemos para aprofundamento a partir dos primeiros levantamentos do estado do conhecimento sobre o tema, com análise de conteúdo de 40 artigos com os indexadores corpo, representações sociais, gênero e autoimagem. Os resultados de cinco categorias de valores encontrados nas similitudes nos permitem lançar discussão acerca da relação entre a representação social de corpo que o docente tem de si e o desempenho docente no enfrentamento de temas afetos ao gênero e a sexualidade.

O corpo é percebido de maneira diferente conforme a sociedade e a local onde este se configura, experiência a vida. No ocidente, influenciado pela cultura capitalista, o corpo é percebido como "material e fisiológico, em que a mente é superior ao corpo". No oriente a visão de corpo é mais sistêmica, pois não se separa a mente e o corpo, formando assim uma só unidade. Essa visão de totalidade favorece a compreensão do ser humano em sua integralidade (SANTOS, 2004 apud PINTO, JESUS, 2000).

A visão fragmentada de corpo do ocidental também se reflete nas disciplinas escolares, filosófica separando-as por partes em diversas áreas, é a visão biologista. Esse posicionamento se repete reiteradas vezes nas profissões da área da saúde, entre elas medicina, odontologia, e educação física.

Para se conhecer como a sociedade apreendeu o corpo em diversas épocas da humanidade, recorremos aos estudos de Santos (2004) e sua organização da fragmentação do corpo nos aspectos anátomo-fisiológico, filosófico, psicológico e sociológico, e nas obras sobre historia do corpo de Corbin, Cortine e Vigarello (2009) e da obra Corpo e Sociedade de Turner (2014).

Iniciando pela materialidade proposta de corpo anátomo-fisiológico deflagra-se a ideia de corpo visto em fragmentos, e as partes observadas de forma separada. Essa visão biologista é fruto da divisão entre corpo e mente. Para Santos (2004) apud Bracht (1999, p. 93) “O corpo é igualado a uma estrutura mecânica - a visão mecanicista do mundo é aplicada ao corpo e a seu funcionamento". Esse olhar sobre o corpo não é algo novo, ele data os tempos da Grécia Clássica.

O corpo filosófico também é visto com a divisão entre corpo e alma, mas estabelece a subordinação do corpo a alma. Na conceção grego-filosófica o corpo está em segundo plano, e a alma é que comando o ser humano. Na conceção corpo religioso-filosófico o corpo é visto 
como instrumento do pecado, enquanto o espírito é interno a este. Esse corpo adquire menos importância em detrimento do espírito.

Santos (2004) continua demonstrando que no corpo psicológico a dualidade continua a existir, pois a separação entre corpo e mente fica evidenciada, quando é a mente que comanda o corpo. O corpo é visto como inferior, subordinado a mente.

O corpo sociológico para Santos (2004) obtém duas visões: o corpo-escultural é o instrumento de alguma ideologia, pode estar a serviço da beleza, da força, da performance. Ela é manipulada conforme interesse mercadológicos, financeiros, e estéticos. O corpo sóciocultural é visto como único, sem a dualidade vista anteriormente, aqui o corpo é influenciado pela cultura e faz parte dela. A corpo é influenciado pela cultura, que se confundem, e andam lado-a-lado, numa só unidade.

Para os diferentes olhares sobre o corpo como o do próprio sujeito sobre seu corpo, o de possessão o de posse do outro, da religião, da medicina ou antropologia, a historicidade do corpo de Corbin e outros (2009) vai traçar o corpo como possibilidade de ser e de pertencer que pode ter contorno de linguagem polissêmica.

O corpo, segundo Corbin (2009, p. 9) também é entendido como "ficção, um conjunto de representações mentais, uma imagem insciente que se elabora, se dissolve, se reconstrói através da história do sujeito, com a mediação dos cursos sociais e dos sistemas simbólicos".

Em Barrenechea (2009, p. 51), o corpo elucidado por Nietzsche explica por que o ser humano tende a criar conceitos substancializantes. Assim, o "corpo é a expressão do dinamismo do vir-a-ser, jamais se fixa, jamais se estabiliza, mudando conforme o impulso ou o grupo de impulsos que, num instante efêmero, impõe sua vontade à comunidade orgânica". Observamos que este entendimento supera a ideia dualista de corpo e alma.

A atividade psicanalítica trabalha com a ideia de corpo para além do que é visto materialmente. $\mathrm{O}$ corpo se distingue entre o corpo orgânico da fisiologia e biologia para corpo sentido. Nele se inscrevem dimensões psíquicas do corpo real, onde se revelam entendimentos da subjetividade do sujeito em relação ao corpo, que "é construído por percepções, representações, investimentos libidinais, pulsão e fantasias mentais. O corpo, então, é inscrito nos registros do simbólico e do imaginário" (NASIO, 2008, p34).

RPI Revista de Pesquisa Interdisciplinar, Cajazeiras, v. 1, Ed. Especial, 114 - 128, set/dez. de 2016. 
As demandas contemporâneas do corpo "como um status culturalmente definido, adquirido através da jovialidade, beleza, aparência de felicidade, e poder de atração sexual" são identificadas por Novaes (2006).

O desejo de eternizar a beleza, a jovialidade, a saúde é uma tendência iniciada na modernidade e atua na contemporaneidade pela busca da eternização da juventude de diferentes modos. No entanto, o paradoxo que se instaura neste século se dá por diferentes caminhos. Entre eles: a mutilação dos corpos, a alteração fisiológica e estética via alimentação errônea, maus tratos e ausência de cuidados com o corpo, seja por excesso de trabalho, seja por desconhecimento ou alguma patologia psíquica, as funções sociais valorizadas culturalmente e transmitidas nas diferentes instituições sociais, em especial nas mídias são fatos sociais que a escola não pode ignorar.

Hoje, já sabemos por inúmeros estudos que as conceções e/ou definições sociais, do corpo, difundidas via processos de comunicação, seja na igreja, na escola, na academia na mídia, forjam as imagens individuais e as representações sociais. Eis a importância de se estudar estas para propormos uma intervenção.

\section{Metodologia}

Ao partir da ideia de que o método não se desvíncula dos aspectos ontológicos e axiológicos do conhecimento (CRESWELL, 2007), esclarecemos que a alegação de conhecimento do nosso trabalho centra-se na a busca de entendimentos que permitam um diálogo entre os participantes do estudo, para servir de orientação na delegação de poder no processo de autoformação. Deste modo, o paradigma eleito para o desenvolvimento do estudo pretendido é de que o conhecimento é sócio culturalmente instituido no e pelo imaginário.

O presente estudo tem como desenho as dimensões de pesquisa propostas por Novikoff (2010), ou seja, um processo de pesquisa não linear, mas dialético, em que cada dimensão é organizada em relaçãoa outra, considerando o lócus da pesquisa e seus participantes. Noutras palavras ela é dinâmica e permite o surgimento de novas questões e processos de coleta de dados, de acordo com a demanda do processo investigatório.

Para melhor compreender as referidas dimensões e sua dinâmica, as descrevemos a seguir, de modo sintético, ressalvando que uma pesquisa nem sempre começa na sequência a ser apresentada.

RPI Revista de Pesquisa Interdisciplinar, Cajazeiras, v. 1, Ed. Especial, 114 - 128, set/dez. de 2016. 
1) dimensão epistemológica: articula o estado do conhecimento do objeto de pesquisa com interrogações sobre o mesmo e o sujeito num determinado contexto e elaboram-se as questões da investigação, os objetivos, as hipóteses em casos de pesquisa quantitativa ou mista, os pressupostos para abordagens qualitativas. Nesta fase, passamos por três etapas: i) apresentação dialógica sobre o objeto de estudo e seu lugar na pesquisa científica; ii) estudos dirigidos de textos, concomitantemente, com o preenchimento de tabela de análise de artigos com os unitermos "corpo", "autoformação", "auto imagem" e "representação social"; iii) elaboração de tabela de projeto, segundo as dimensões propostas por Novikoff (2010).

2) dimensão teórica: trabalha a revisão da literatura de modo mais aprofundado, com fichamentos e análises critica da teoria. Se na dimensão epistemológica importava verificar o que havia de pesquisa similar, agora a proposta é revisar os questionamentos e os objetivos elaborados no projeto para marcar seus limites, propiciando mais segurança no recorte teórico a ser tratado.

3) dimensão técnica: visa delinear o método de estudo, definir a natureza da pesquisa, as formas de coleta de dados e a amostra;

4) dimensão morfológica: descreve como os dados serão apresentados (gráficos, tabelas, etc.); Aqui a discussão é sempre pareada e os dados são tratados no programa Excell com fórmulas próprias, especialmente desenvolvida para esta finalidade, gerador de gráficos e tabelas.

5) dimensão analítico-conclusiva: tece a análise confrontando os dados a teoria e aos objetivos propostos. Responde as questões elaboradas e apresenta as conclusões.

Em relação à Dimensão Técnica, nossa pesquisa é de natureza qualitativa do tipo bibliográfica, documental sob a abordagem etnografica (MATTOS, 2001, BREWER, 2009; ANDRÈ, 1995).

A etnografia como abordagem de investigação científica exige cuidado na percepção da realidade, ou seja, na análise dialética da cultura, entendida como um sistema de significados mediadores entre as estruturas sociais e a ação humana os professores em estudo tem tido uma participação ativa e dinâmica no processo educacional de modo lato - na própria estrutura política da profissão. Estas relações e interações ocorridas no interior da escola, vem proporcionando alguns indicios (GRINZBURG) dos entreaves na realçao de ensinoaprendizagem.

RPI Revista de Pesquisa Interdisciplinar, Cajazeiras, v. 1, Ed. Especial, 114 - 128, set/dez. de 2016. 
Ao se entender que a etnografia se desenvolve num processo norteado pelo senso questionador do etnógrafo é possível assinalar que a utilização de técnicas e procedimentos etnográficos, "não segue padrões rígidos ou pré-determinados, mas sim, o senso que o etnógrafo desenvolve a partir do trabalho de campo no contexto social da pesquisa." (MATTOS, 2001, p. 1). Noutras palavras, as técnicas são determinadas em razão das questoes levantadas na pesquisa. No caso, em apreço, o fato de observarmos os participantes do estudo no próprio local de trabalho nos possibilitou elencar algumas técnicas de coleta de dados que aqui passaremos a descrever.

A coleta de dados para o estudo vem se delineando via estudo do conhecimento, revisão bibliográfica e coleta de dados diretamento junto aso participantes via entrevista, teste de associação livre de palavras, entrevista focal.

Em relação ao estudo bibliograficos, inicialmente, se deu pelo estudo do conhecimento via Tabela de Análise de Textos Acadêmicos e Científicos das Dimensões de pesquisa propostos por Novikoff - TabDN proposat por Novikoff (2010). A tabela TabDN permite o aprofundamento e revisão dos textos de modo a enriquecer a redação final.

A coleta de dados diretos dos participantes foi realizada em duas etapas. Na primeira etapa da pesquisa, realizou-se um teste de evocação livre de palavras, usando como instrumento a técnica projetiva de desenho adaptado de Garcia e Novikoff (2012). Assim, na primeira etapa do trabalho de campo elaboramos um teste de associação livre de palavras. Esta estratégia foi utilizada porque permite surgir espontaneamente palavras associadas ao corpo, colocando em evidência a sua articulação com a palavra induzida (ABRIC, 1998). Aqui foi solicitado do sujeito que escrevesse as palavras que imediatamente associa ao ouvir o termo corpo e, em seguida desenhe o seu corpo.

Para Bardin (1979), a utilização do teste de associação ou evocação livre de palavras tem se mostrado útil nos estudos dos estereótipos, percepções e atitudes que são compartilhados por este grupo e que são importantes no estudo da estrutura e organização das representações sociais. Consiste em se solicitar ao sujeito que liste um número determinado de palavras ou expressões que julgue estar associadas ao termo indutor. Estas associações podem ser adjetivos, substantivos, advérbios ou verbos, nomes próprios ou expressões diversas, a juízo dos sujeitos.

As inúmeras evocações realizadas, depois de listadas, compuseram um conjunto diversificado e heterogêneo de unidades semânticas, que ainda deverão ser organizadas e RPI Revista de Pesquisa Interdisciplinar, Cajazeiras, v. 1, Ed. Especial, 114 - 128, set/dez. de 2016. 
classificadas em grupos de sinônimos ou com proximidade semântica, para que possa facilitar o trabalho de análises descritivas e explicativas do objeto considerado, para se chegar à estrutura e organização das representações sociais do objeto em estudo (TURA, 1998). Desta forma, espera-se obter um corpus, que possibilitará identificar as frequências e a ordem das evocações e a respectiva classificação em unidades de significação.

Também foi usado para conhecer os sujeitos, um questionário sociocultural que visa identificar a situação sociocultural, a mobilidade social e os valores e normas atribuídas pelo sujeito ao corpo.

Os termos distribuídos em uma grade de indicadores serão confrontados com as categorias de valores (NOVIKOFF, 2006).

Cabe apontar que todos os envolvidos preencheram Termo de Consentimento Livre e Esclarecido de acordo com as normas da Resolução n 466, do Conselho Nacional de Saúde de 12/12/2012, atendendo a normativa do Comitê de Ética e Pesquisa com seres humanos. O desenho do estudo considera, ainda, dentro das dimensões supracitadas, permitir aos professores participantes do estudo, se encontrarem no complexo trabalho docente em sala de aula e, por meio das próprias narrativas e imagens, exercitar reflexões e traçar estratégias de enfrentamento que os permitam superar formas esvaziadas do ser professor e fortalecer sua autoimagem.

Nesta linha de entendimento sobre o valor da pesquisa qualitativa, o projeto percorreu sete etapas, a saber: 1) Contrato de pesquisa, momento da pré-entrevista para explicar o projeto, firmar acordos de trabalho-pesquisa e assinar o "Termo de Consentimento Livre e Esclarecido - TCLE e a declaração de autorização de uso de imagens. Esta primeira etapa consistirá em conversa com os (as) professores (as) interessados na pesquisa, seguindo para um planejamento das atividades; 2) Aplicação do teste de associação livre de palavras (TALP) em que os dados oriundos deste instrumento serão analisados com a utilização do software EVOC 2000; 3) Aplicação de questionário socio-cultural; 4) Análise de narrativas escrita e oral; 5) Análise dos roteiros de discussão sobre a autoanálise elaboradas pelo próprio professor (a) do banco de dados do Lageres; 6) Círculo de discussão individual no qual serão apresentadas imagens e textos para cooperação nas reflexões; 7) Círculo de discussão grupal, com todos participando das discussões em forma de grupo focal, onde a liderança do moderador dirige suas questões geradoras de uma discussão na qual os participantes reagem 
uns aos outros, sem, porém, que haja polêmica ou, caso haja, que seja tratada com ética (GASKELL, 2003, p. 79 in BAUER; GASKEL, 2003).

Na pesquisa a que se refere este texto, o trabalho de campo se encerrará quando se avalidar que com o material obtido será possível: 1) identificar padrões simbólicos e práticas empregadas no universo estudado; 2) descrever e analisar diferentes trajetórias profissionais e construir hipóteses relativas ao processo de formação e de socialização profissional; 3) identificar valores, conceções, ideias, referenciais simbólicos que organizam as relações no interior desse meio profissional, buscando compreender seus códigos, o ethos profissional, mitos, rituais de consagração e legitimação, diferentes visões de cinema e conceções de aprendizagem do ofício e 4) configurar algum nível de generalização no que dizia respeito a essa categoria profissional, ao seu sistema de aprendizagem, regras de funcionamento, relação com o trabalho, rituais de ingresso e de consagração e assim por diante.

\section{Alguns apontamentos de encerramento}

As representações sociais como parte do imaginário social é carregado de ideias, valores, crenças que se articulam e se organizam de modos específicos e singulares em busca de significados e sentidos as coisas, ao ente, como demonstra Castoriadis (1987).

Importa destacar o imaginário, como Castoriadis (1987) trabalha, distingue-se de Kant, Freud e outros, a partir da ideia de imagem que é uma criação incessante e essencialmente indeterminada de formas e figuras, concomitantemente é a realidade e racionalidade resultante de processos psíquicos e históricos sociais. Portanto, o imaginário não é um símbolo ou sinal, mas todos os símbolos e todo o simbolismo tem um componente imaginário, o que significa que o imaginário é revelado no símbolo e existe para a força imaginária.

Dentro dessa perspectiva, os símbolos ao obedecer a uma lógica, uma dada racionalidade apropriada para eles podem ser representados por via oral, escrita e gestual. Vale pontuar que seguem uma lógica que não é apenas pura, ou abstrata, nem totalmente lúcida. Eles são colocados sobre o âmbito do coletivo anônimo, ou seja, cai na sociedade, e é na singular mente humana, ou alma, enquanto imaginário radical que são criados. É a representação de alguma coisa ou algo para alguém.

RPI Revista de Pesquisa Interdisciplinar, Cajazeiras, v. 1, Ed. Especial, 114 - 128, set/dez. de 2016. 
$\mathrm{Na}$ Teoria das Representações Sociais de Moscovici, o fenômeno de construção de uma ideia, de um conhecimento de valores sobre algo se apresentam como algo com conteúdo, ou seja, de algo com uma estrutura conceitual e funcional que podem apreendidas para ampliar nosso entendimento sobre um dado fenômeno social. Lembramos que esta teoria favorece tecer alguns indícios de uma possível justificativa das práticas e propor a resolução de problemas sem ser por modelos prontos, mas discutir com o envolvido os caminhos na busca de melhores estratégias pedagógicas.

Para Moscovici (2003, p. 43), as representações sociais devem ser consideradas não como conceitos, mas como fenômenos sociais. Assim, elas devem ser vistas como uma maneira específica de compreender e comunicar o que já sabemos. Eles ocupam, com efeito, uma posição curiosa, em algum lugar entre os conceitos, que têm como seu sentido objetivo abstrata do mundo e entrou na ordem de percepções, que reproduzem o mundo de uma forma significativa.

A reprodução do mundo na formação docente é perceptível na literatura pedagógica sobre a formação de professor por competência ou saberes docentes que não podendo dar conta de uma compreensão radical e genealógica e desterritorializada do conjunto discursivo que se inserem.

Encerramos ao apontar a necessidade de desenvolver e instigar a cognição, a racionalidade critica sobre o corpo nos cursos de formação de professores. Mas, não a cognição mimética, apesar de seu lugar estar guardado, mas aquela que não se reduz à mnemônica e a solução de problemas, mas é uma ação produtiva que faz emergir o si e o mundo no corpo e com o corpo.

\section{REFERÊNCIAS}

ABRIC, Jean Claude.( 1998). A abordagem estrutural das representações sociais. In: MOREIRA, A .S. P. e OLIVEIRA, Denise Cristina (orgs) Estudos Interdisciplinares de Representação Social. Goiânia: AB, p.328.

ANDRÈ, Marli Eliza D.A. de. Etnografia da prática escolar. $5^{\text {a }}$ edição. Campinas, SP: Papirus, 1995.

BARRENECHEA, Miguel. (2010). Nietzsche e o corpo. Rio de Janeiro: 7 letras.

BAUER, M. W.\& GASKELL, G. (2003). Pesquisa qualitativa com texto, imagem e som: um manual prático. $2^{\mathrm{a} e d . P e d r i n h o ~ A . ~ G u a r e c h i ~(T r a d) . ~ P e t r o ́ p o l i s: ~ E d i t o r a ~ V o z e s . ~}$ 
BREWER, John. D.(2009). Ethnography. London, UK, Open University Press: McGraw.

CRESWELL, John W. (2005). Projeto de Pesquisa: métodos qualitativo, quantitativo e misto. Porto Alegre: Artmed.

FREIRE, Paulo; SHOR, Ira. (1986). Medo e ousadia - o cotidiano do professor. Rio de Janeiro: Paz e Terra.

FREIRE, Paulo. (2005). Pedagogia do Oprimido, 49ª reimpressão, Paz e Terra. (1996). Pedagogia da Autonomia. 9ª Ed. São Paulo: Paz e Terra.

GATTI, B.A.; BARRETO, E.S.S. (2009). Professores: aspectos de sua profissionalização, formação e valorização social. Brasília, DF: UNESCO.

JACÓ-VILELA, AM., and SATO, L. (orgs.). (2012). Diálogos em psicologia social [online]. Rio de Janeiro: Centro Edelstein de Pesquisas Sociais.

JODELET, Denise (Org.). (2001). As Representações Sociais. Rio de Janeiro: EdUERJ.

JODELET, Denise. Experiência e representações sociais. (2005). In MENIN, Maria Suzana De S.; SHIMIZU, A. de M. Experiência e Representação Social: questões teórico e metodológicas. São Paulo: Casa do Psicólogo.

(2009). O movimento de retorno ao sujeito e a abordagem das representações sociais. Sociedade e Estado, Brasília, v. 24, n. 3, p. 679-712, set./dez.

MATTOS, Carmen Lúcia Guimarães de; FONTOURA, Helena Amaral da.(2009). Etnografia e Educação. Organização Rio de Janeiro: Eduerj.

MATTOS,C. L. G. De (2001). A abordagem etnográfica na investigação científica. UERJ.

MORIN, E. (1994). Introdução ao pensamento complexo. Lisboa: Instituto Piaget.

MOSCOVICI, Serge. (1978). A Representação Social sobre a Psicanálise. Rio de janeiro: Zahar Editores.

Ed.:Vozes.

.(2003). Representações Sociais: investigações em psicologia social. Petrópolis:

NASIO, J.D. (2008). Meu corpo e suas imagens (A.Telles, trad.) Rio de Janeiro: Jorge Zahar.

NIETZSCH. (2005). Humano, Demasiado Humano. In: Pensadores. São Paulo: Nova Cultural.

NIETZSCHE, F. (2005). Sobre Verdade e Mentira no Sentido Extramoral. In: Pensadores. São Paulo: Nova cultural.

NOVAES, J. (2006). O intolerável peso da feiúra: sobre as mulheres e seus corpos. Rio de Janeiro: Ed. PUC/ Garamond.

NOVIKOFF, C. (2010). Dimensões Novikoff: um constructo para o ensino-aprendizado da pesquisa. In ROCHA, J.G. e NOVIKOFF, C. (orgs.). Desafios da práxis educacional à 
promoção humana na contemporaneidade. Rio de Janeiro: Espalhafato Comunicação, p. 211-242.

(2006). As Representações Sociais Acerca do Ensino Superior para professores de graduação na área da saúde. Tese (Doutorado em Educação: Psicologia da Educação), São Paulo: Pontifícia Universidade Católica de São Paulo.

POMBO, Olga. (2004). Interdisciplinaridade: ambições e limites. Lisboa: Relógio d'Água.

REHFELD, A.(2004) Corpo e Corporeidade: uma leitura fenomenológica. Revista de Psicologia do Instituto de Gestalt de São Paulo, n.1.

SÁ, Celso P. (1996) . Núcleo Central das Representações Sociais. Petrópolis: Voze. 